\title{
Applied Technosphere Riskology as Direction of Future Life Security Experts Vocational Training
}

\author{
Elena Viktorovna Muravyeva ${ }^{1}$, Marina Viktorovna Golovko ${ }^{1}$, Shamil Rinatovich Yusupov ${ }^{2}$, Raisa Gabdullovna \\ Biktemirova $^{2}$, Galina Viktorovna Morozova ${ }^{2}$ \& Tatyana Timofeyevna Sidelnikova ${ }^{2}$ \\ ${ }^{1}$ Kazan National Research Technical University named after A.N. Tupolev, Tatarstan, Russia \\ 2.Kazan (Volga region) Federal University, Kazan, Russia \\ Correspondence: Elena Viktorovna Muravyeva, Department of Industrial and Environmental Safety, Kazan \\ National Research Technical University named after A.N. Tupolev, Kazan, 420111, Russia. E-mail: \\ elena-kzn@mail.ru
}

Received: September 22, 2014 Accepted: November 5, 2014 Online Published: December 2, 2014

doi:10.5539/ass.v11n1p142 URL: http://dx.doi.org/10.5539/ass.v11n1p142

\begin{abstract}
Theoretical and practice-oriented bases of applied technosphere riskology as a new interdisciplinary direction of students training at technical educational institutions are revealed in the article. Specialized technology of the risk management, urged to solve problems of technosphere safety taken as a whole, but not separate parts is the main research of the article. "The applied technosphere riskology" is logical development of rather new scientific and subject matter - riskology - as for life security of a person is concerned. The authors have considered interdisciplinary integration in the content formation of vocational training of future life security experts in the field of applied technosphere riskology, and also practice-oriented aspects of a graphic-analytical method "treelike structures" and a method of the diversionary analysis, directed at risk thinking formation, at professional reflection and culture of students life security as they are future life security experts. The article will be useful for technical college teachers, the theorists and practitioners who are studying questions of the analysis, forecasting and risk management in technosphere.
\end{abstract}

Keywords: co-evolutionary strategy, applied technosphere riskology, risk management, interdisciplinary integration, graphic-analytical method "treelike structures", method of the diversionary analysis

\section{Introduction}

Judging by deterioration of environment condition, it is obvious that the culture of technocratic society practically exhausted the opportunities, resulted in instability of fragile balance between technosphere and biosphere; it turned out to be incapable to support the level of relationship necessary for providing stable development of the civilization and put the mankind, as a species, on a brink of survival. The developing situation demands to take measures to improve management of safety in connection with the quantity increasing of annually arising of emergency situations of natural and anthropogenic character. Anthropogenic threats acquire complex measures now. The object or subject is affected by several factors at once that it is much more dangerous, than independent influence of the same factors (Gorshkov, 1995).

Possibility of current overcoming situation is seen in transition to new civilized models which cornerstone co-evolutionary strategy, i.e. strategy of implementation of a parallel stable development of nature, society, culture and a person himself (Gorshkov, 1995; Danilov-Danil'yan, 2000; Mamedov, 1996; Nebel, 1993).

The embodiment of this model in life requires development of new thinking, in the field of safe coexistence of nature and a technosphere which could change mentality of society in general and experts in technical areas, in particular, for essentially different relationship with environment.

In this regard, special relevance is gained in modern conditions by a problem of vocational training of experts in technical field who are urged to expect results of the practical activities in technosphere, to resolve the issues connected not only with understanding of risks of anthropogenic catastrophes, safety of people, but also with questions of effective management of these risks, their prevention or minimization.

For the purpose of bringing vocational training of life security experts into compliance with modern requirements of safety of technological productions and minimization of their destroying impact on environment, 
as a whole we offer and we approve in practice the specialized, accurately defined scientific direction "applied technosphere riskology" on the basis of the Kazan State Technical University named after A.N.Tupolev. Applied technosphere riskology is an interdisciplinary direction synthesizing theoretical and practical results of sciences about surrounding world in development of conscious use of knowledge about synergism of anthropogenic, ecological, social factors in risk management of complicated anthropogenic complexes, acting as pedagogically interpreted system knowledge, that allows carrying out a pedagogical goal-setting, forecasting and modern technification of future engineers vocational training (Romanovsky \& Muravyeva, 2007).

\section{Literature Review}

There was a certain direction of works under the general name "Management of Risk" in problem of risk researches. There are some names for management of risk process both in our country (providing of industrial safety), and abroad ("safety management", "management of process hazards") which are actually synonyms. These terms are understood as set of the actions directed at decreasing of technological risk, reduction of potential financial losses and other negative consequences of accidents. Thus it is necessary to consider that risks, unlike dangers of last eras, are a consequence of the menacing force of modernization and feelings of uncertainty and fear generated by it" (Yanitsky, 1999).

The most important social features of risk are marked out in the work of German sociologist U. Beck "Society of risk": firstly the risk is always created in social system; secondly the volume of risk is a function of quality of the social relations and processes; and the third, degree of risk depends on experts and expert knowledge (Beck).

The term "riskology" is used in some works connected with risk problems. Its sense is treated by the authors differently:

- O.N. Yanitsky (Yanitsky): "riskology is a subject that does not mean risks and accidents with their consequences, but society in which production, distribution and consumption of risks is immanently inherent";

- V.V. Otkidach, S.G. Dzhur, O.V. Fisurenko (Otkidach, 2004): "... the science about risk is necessary. This science is riskology. Riskology is a science about the future because it is connected with projections, possible outcomes, the future accidents";

- O. Lisitsyna (Lisitsyna): "The concept studying risks is called riskology".

Donald Schoon emphasized in the concept of reflective practitioner perspective that formation of abilities of critical judgment of possible consequences and results of practical activities is an important factor of efficiency activity providing (Schoon, 1987).

As far as the responsibility of engineers has increased greatly because of the development of technosphere so the requirements to the level of their vocational training have to be increased too.

There are a lot of scientific researches which are devoted to riskology as a science in general (Belov, 2003; Buyanov, 2003; Vishnyakov, 2001; Kasyanov, 2003; Pushkina \& Emelyanov, 2005), but theoretical and practice-oriented bases of an applied technosphere riskology devoted to riskology as interdisciplinary direction of future life security engineers training remains the area of theoretical and applied knowledge that is not studied enough nowadays.

\section{Results and Discussions}

\subsection{The Purposes and the Principles of Qualified Life Security Experts' Vocational Training in the Field of Applied Technosphere Riskology}

Main objectives of qualified life security experts' vocational training in the context of an applied technosphere riskology are: formation of competences, including ecological competence, on providing collective security while performing practical activities, forming risk- thinking, professional reflection, culture of future engineers' life security, knowledge and abilities which allowed expecting possible consequences and risks of the made decisions, to operate these risks, to prevent or minimize them.

Such principles as problematical character, theoretical validity and establishment of causative-consecutive and logical communications between the studied questions, a practical orientation of training are put at the heart of vocational training of future engineers.

The main requirement to vocational training of future engineer is the interdisciplinarity, that means difficult system tendencies in science and technologies which make more and more multilateral impact on environment and society (Global Studies: An Encyclopedia, 2003) and the applied technosphere riskology has to play a backbone role in this process. 


\subsection{Interdisciplinary Integration as a Basis of Qualified Life Security Experts' Vocational Training in the Context of an Applied Technosphere Riskology}

Table 1. Elements of applied technosphere riskology in the subjects of the specialty "Protection in Emergency Situations"

\begin{tabular}{|c|c|c|}
\hline Subjects & Course & Elements of applied technosphere riskology \\
\hline Introduction to the course & 1 & $\begin{array}{l}\text { Need of knowledge of the theory of risk for future profession, its role in life } \\
\text { security is explained. }\end{array}$ \\
\hline Physics & $1-2$ & An idea of risks minimization in power balance of the biosphere is given. \\
\hline Economics & 1 & $\begin{array}{l}\text { An idea of economic risk, its interrelation with technological, ecological, social } \\
\text { risks and risk in environmental management is given. }\end{array}$ \\
\hline Higher mathematics & $1-2$ & $\begin{array}{l}\text { Acquaintance to mathematical apparatus for calculations of risks, method of } \\
\text { mathematical modeling. }\end{array}$ \\
\hline Philosophy & 2 & An idea of risk philosophy is given. \\
\hline Sociology & 2 & $\begin{array}{l}\text { An idea of social risk, its interrelation with technological, ecological risks and risk } \\
\text { in environmental management is given. }\end{array}$ \\
\hline Ecology & 3 & $\begin{array}{l}\text { An idea of an environmental risk, its interrelation with other types of risks, } \\
\text { possibility of management by an environmental risk is given. }\end{array}$ \\
\hline $\begin{array}{l}\text { Medical biological } \\
\text { fundamentals of life security }\end{array}$ & 3 & An idea of toxicological risk, its interrelation with other types of risks is given. \\
\hline $\begin{array}{l}\text { Physical and chemical processes } \\
\text { in a technosphere }\end{array}$ & 3 & $\begin{array}{l}\text { An idea of physical and chemical processes in production as integral part of } \\
\text { knowledge in the analysis of identification of technological hazards and the risk of } \\
\text { emergence during physical and chemical modeling of emergency situation is given }\end{array}$ \\
\hline $\begin{array}{l}\text { Reliability of technical systems } \\
\text { and anthropogenic risk }\end{array}$ & 3 & Bases of the theory of risk, risk analysis, management of risk, admissible risk. \\
\hline Undergradu & 4 & An \\
\hline Dangerous nature processes & 4 & $\begin{array}{l}\text { An idea of starting risk of dangerous nature processes is given. Interrelation with } \\
\text { other risks. Management of this risk. }\end{array}$ \\
\hline $\begin{array}{l}\text { Psychological stability in } \\
\text { emergency }\end{array}$ & 4 & An ic \\
\hline Fire and explosion protection & 4 & $\begin{array}{l}\text { Definition of risk influence of dangerous factors on staff and population. } \\
\text { Management of risk in fire protection. }\end{array}$ \\
\hline $\begin{array}{l}\text { Undergraduate's thesis in fire } \\
\text { and explosion protection }\end{array}$ & 4 & Obligatory section in risk calculation, creation of treelike structure. \\
\hline $\begin{array}{l}\text { Stability of economics' objects } \\
\text { (SEO) }\end{array}$ & 4 & $\begin{array}{l}\mathrm{k} \text { theory and management of safety in the context of } \\
\text { here complexes in emergency. }\end{array}$ \\
\hline Undergraduate's thesis on SEO & 4 & An obligatory section in risk calculation. creation of treelike structure. \\
\hline $\begin{array}{l}\text { Planning, organization of civil } \\
\text { protection }\end{array}$ & 4 & ts of risk theory in managing of civil protection powers. \\
\hline $\begin{array}{l}\text { Organization of rescue work } \\
\text { (ORW) }\end{array}$ & 4 & Organization of rescue work taking risk into consideration. \\
\hline Undergraduate's thesis on ORW : & 5 & Obligatory section in risk calculation, creation of treelike structure. \\
\hline $\begin{array}{l}\text { Undergraduate's thesis on } \\
\text { ecological safety }\end{array}$ & 5 & The obligatory section about calculation of risks, creation of treelike structure. \\
\hline $\begin{array}{l}\text { System and providing with } \\
\text { protection management in } 5 \\
\text { emergency }\end{array}$ & 5 & An idea of complex risk management in emergency is given. \\
\hline Radiochemical protection & 5 & An idea of radiochemical risk in emergency is given. \\
\hline $\begin{array}{l}\text { Informational technology in } 5 \\
\text { emergency management. }\end{array}$ & $\begin{array}{l}5 \\
5\end{array}$ & $\begin{array}{l}\text { Computer and informational technologies using in a system of emergency } \\
\text { management is given }\end{array}$ \\
\hline Graduate's intersubjective thesis & & The obligatory section about calculation of risks, creation of treelike structure \\
\hline
\end{tabular}

Interdisciplinary integration as a basis of qualified life security experts' vocational training in the context of an applied technosphere riskology provides implicit inclusion of components of the risk theory and an ecological component in the majority of the studied subjects. The special attention should be paid to such subjects as ecology, reliability of technical systems and anthropogenic risk, environmental management, modeling of 
processes in a technosphere, natural hazards; however this transfer doesn't exclude the necessity of inclusion of components of an applied technosphere riskology in the other subjects.

Now it is necessary to figure out how to introduce an applied technosphere riskology into educational process, without having academic hours for it in the syllabus. As far as the applied technosphere riskology acts as pedagogically interpreted system knowledge in formation of educational process which allows carrying out a pedagogical goal-setting, forecasting and modern technification of future engineers vocational training, the concrete embodiment of it depends on the department policy and desire of each of teachers to realize the introduction of elements of applied technosphere riskology into lectures in practice.

Let us pay attention to some examples of successful symbiosis of subjects on the basis of applied technosphere riskology from the authors' point of view.

According to the state educational standard, the subject "Reliability of technical systems and anthropogenic risk" has to consider the following questions: reliability as complex property of technical object ( device, car, system); essence of reliability as abilities to carry out the set functions, keeping the main characteristics in the set limits, under certain conditions of operation; safety, durability and keeping as main components of reliability; nomenclature of the main sources of accidents and disasters; statistics of accidents and disasters; classification of accidents and disasters; forecasting of accidents and disasters; the accident rate reasons at the enterprises; emergency readiness; emergency reaction; bases of the risk theory; risk analysis; admissible risk; management of risk.

In spite of the fact that the subject "Reliability of technical systems and anthropogenic risk" is given in the sixth semester and is finished with exam, the term paper is planned in the seventh semester, without granting hours for practical training. There is a question how to do the term paper and what has to become its cornerstone? There is the answer in the definition of applied technosphere riskology as the interdisciplinary direction synthesizing theory and practice of sciences in development of conscious use of anthropogenic knowledge synergism, ecological, social and other factors in risk management of difficult technosphere complexes, i.e. it is necessary to use interdisciplinary communications.

Practice has showed that writing a term paper on the basis of subjects "Environmental management" for the specialty "Life Security in Technosphere" and "Natural hazards" for the specialty "Protection in Emergency Situations" will be the optimum decision. Both subjects are given in the seventh semester and only lecture hours are allocated for them, and practical and seminar training isn't provided, therefore, writing of a term paper on "Reliability of technical systems and anthropogenic risk" (RTS and AR) from position of environmental management or emergency situations of natural character will allow reinforcing lecture material. Since future expert has to understand the situation which develops in the region where he is going to work further, term papers have to take into account a regional component. From this point of view, the main sense of carried-out work includes the analysis of one of the regions of Tatarstan from positions of regional security.

\subsection{Algorithm of Writing and the Approximate Maintenance of an Interdisciplinary Term Paper on the Subject "Reliability of Technical Systems and Anthropogenic Risk" (RTS and AR)}

We will give the algorithm of writing an interdisciplinary term paper developed by us as an example on the subject "Reliability of technical systems and anthropogenic risk" (RTS and AR):

1. To consider one of the regions of Tatarstan as an object of research.

2. To consider current situation of anthropogenic impact on the environment.

3. To analyze it from the point of view of the previous man-caused influence.

4. To try forecasting.

5. To choose any object on the region territory and to carry out its detailed analysis (see item 2,3,4).

6. To use a method of treelike structures in the work.

Here is an example of a term paper of the student who is majoring for the specialties "Protection in Emergency Situations", on the subject "Natural Hazards of Chistopolsky Region of Tatarstan".

Contents:

1. Introduction.

2. Purposes and problems of an assessment of risks.

3. Characteristic of the Chistopolsky municipal area. 
3.1 List of potentially dangerous objects of the Chistopolsky area.

4. JSC Chistopolsky Meat-processing Plant description.

5. Methodology of an assessment of risk.

6. The description of applied methods of an assessment of risk and justification of their use.

7. Assessment of emergency risk situations at the enterprise.

8. Analysis of an assessment of risk results.

9. Conclusions and recommendations about development of actions directed at decrease in risk of emergency situations at the enterprise.

\section{Appendix}

\subsection{Active and Interactive Methods of Training in the Course of Vocational Training}

As the content of training in modern conditions can't be considered in a separation from the use in educational process of active and interactive methods of training, it is necessary to focus attention on the course of formation and development risk thinking, professional reflection, culture of life security of future experts in the field of protection in emergency situations one of effective methods are a graphic-analytical method "treelike structures" and a method of "the diversionary analysis" (Muravyeva \& Romanovsky, 2010).

In the course of vocational training students learn to analyze events by means of a graphic-analytical method "treelike structures" at the practical classes. Their essence includes graphical representation of interrelation of different events of a system "person - technics - environment", the analysis not only negative, but also positive states and purposes. This method has a number of advantages: promotes accurate formalization of a considered material; it is focused on the analysis of various situations; gives the chance of the analysis of various interconnected situations and events; gives the chance of an effective quantitative assessment of probability of achieving an analyzed event; it is equal to all elements of person-technics-environment system. Use of this method gives a chance to a student (further - to the engineer) to define risk zones and to predict the possible emergency situations, capable to cause damage to the population, production objects and environment.

Method of the diversionary analysis is a method of emergency situations forecasting, accidents, disasters, natural disasters, etc., and also identifications of the reasons of already happened incidents. It consists of two main stages. At the first stage there is a transformation of questions like, "what emergency situations and the undesirable phenomena are possible in this object", or "why there was this emergency situation" into questions like, "how to provide emergence of the greatest number of the most dangerous undesirable phenomena", or "how to realize that very emergency situation ". At the second stage problems of prevention of predicted "diversions" at the enterprise are solved. Thus "the diversionary analysis" includes previously carried-out operations: formulation of "a diversionary task"; analysis of known ways of creation of the emergency situations harmful and undesirable phenomena; certification and check of opportunities of use for "diversion" of available resources; search of possible undesirable effects in information funds and by means of methods of technical creativity; search of opportunities of strengthening and "masking" undesirable effects; the analysis of the revealed undesirable effects and opportunities of their strengthening; search of opportunities of elimination of undesirable effects. Such approach, further, involves use of the script analysis, which includes creation of two or three plausible scripts, development of adequate strategy for each of them, an assessment of probability of implementation of scripts and an assessment of resultant strategy. Accurate systematization of existing risks is necessary for acceleration of process of scripts development and a choice of strategy.

\section{Conclusion}

Thus, it is necessary to form a specialized, accurately defined direction "Applied Technosphere Riskology" in the field of knowledge "Life security in technosphere". Actually it is a new type of technology - the technology of risk management considering and solving a wide range of interconnected questions (technical, ecological, social and economic, informational, political, etc.) for identification of "weak" points in the existing or created technosphere systems for the subsequent optimization of security measures and decrease in probability of emergency situations of natural and anthropogenic character.

The applied technosphere riskology allows carrying out intersubject integration since the first year till protection of final qualification work that gives future engineers a complete idea of a functioning of technosphere complexes in the context of ecological, anthropogenic and social safety. It promotes formation of engineering competences. Logically arranged training of experts has to promote risk reflection formation and culture of future engineers' life security from the point of view of risk thinking formation. The expert who has knowledge 
and competences in risk management of difficult technosphere complexes is capable to make competent professional solutions from positions of prevention or minimization of risks that will promote increase of life security.

\section{References}

Assessment and Management of Natural Risks. Thematic volume. (2003). Moscow: Publishing House Crook.

Beck, U. (n. d.). Risk Society. Toward a New Modernity. London: Sage Publications.

Belov, P. G. (2003). System Analysis and Modeling of Hazardous Processes in the Technosphere. Moscow: Publishing Center Akademiya.

Buyanov, V. P. (2003). Riskologiya (risk management). Moscow: Publishing House Examination.

Danilov-Danil'yan, V. I. (2000). Environmental Challenges and Sustainable Development. Moscow: Publishing House Progress-Tradition.

Global Studies: An Encyclopedia. (2003). Moscow: Publishing House Rainbow, 1328.

Gorshkov, V. G. (1995). Physical and Biological Bases of Life Stability. Moscow: Publishing House Nauka. http://dx.doi.org/10.1007/978-3-642-85001-1

Grishaev, V. V. (n. d.). Risk and Society. Retrieved from http://www.ecsocmanedu.ru/db/msg/

Kasyanov, N. L. (2003). Environmental Risks and Geodynamics. Moscow: Publishing House Science World.

Mamedov, N. M. (1996). Culture, Ecology, Education. Moscow: Publishing REFPA.

Muravyeva, E. V., \& Romanovsky, V. L. (2010). «Risk-thinking, as the Most Important Professional Competence of Security Experts». International Science Journal. Acta Universitatis Pantica Euxinus Special Issue, 206-209.

Nebel, B. (1993). Environmental Science: How the World Works. Moscow: Publishing House Mir.

Otkidach, V. V., Dzhur, S. G., \& Fisurenko, O. V. (2004). Riskologiya - Risk Management. Risks of Modern World: Identification and Protection. Proceedings of the VIII International Scientific Conference of the International Academy of Ecology and Life Safety. St. Petersburg, 46-49. Retrieved from http://www.uran.donetsk.ua/ masters/2006/kita/mayir/library/art02.htm

Pushkina, Y., \& Emelyanov, A. (2005). Accounting Synergy Potential and Situational Risk when Managing Technological Risks. Collection of scientific papers and articles 1st International conference Security. Technology. Management. Tolyatti: Tolyatti State University Publishing House.

Romanovsky, V. L., \& Muravyeva, E. V. (2007). Applied Technosphere Riskology. Environmental Aspects. Kazan: Publishing RITZ School.

Schoon, D. A. (1987). Educating the Reflective Practitioner: Towards a New Design for Teaching and Leaning in the Profession. Jossey-Bass.

Vishnyakov, Y. D. (2001). How to Teach Risk Management and Security: An Analysis of the Situation. Journal of Ecology and Industry of Russia, 8, 32-38.

Yanitsky, O. N. (1999). Models and Mechanisms of Russian Environmental Policy. Journal of Sociological Research, 4, 21-22.

\section{Copyrights}

Copyright for this article is retained by the author(s), with first publication rights granted to the journal.

This is an open-access article distributed under the terms and conditions of the Creative Commons Attribution license (http://creativecommons.org/licenses/by/3.0/). 